Гасанова Г.А. Эпитеты как одно из основных средств создания художественных образов в произведениях Э. Капиева

УДК 894.612.6 Капиев.06

DOI: $10.21779 / 2542-0313-2019-34-3-55-64$

\title{
Г.А. Гасанова
}

\section{Эпитеты как одно из основных средств создания художественных образов в произведениях Э. Капиева}

Дагестанский государственьй университет; Россия, 367000, г. Махачкала, ул. М. Гаджиева, 43a; gulistan160459@mail.ru

В статье рассматриваются эпитеты-прилагательные на материале прозаических произведений известного дагестанского писателя-билингва Эффенди Капиева. Он использует различные по семантике и структуре эпитеты-прилагательные, способствующие выразительному и эмоциональному изображению героев, а также окружающей их природы. В произведениях писателя широко представлены эпитеты-колоративы, что свидетельствует об особенном изобразительном языке автора. Обращается внимание на индивидуально-авторские метафорические эпитеты, с помощью которых автором создаются оригинальные, яркие, национально-специфичные художественные образы. Отмечается национально-культурная специфика капиевских эпитетов. Особо выделены эпитеты-прилагательные, описывающие реалии горского быта и природу родного края, свидетельствующие о его большой любви к Родине. В своих произведениях автор использует также национально-культурные лексические единицы, передающие особенности местного колорита и придающие произведениям реалистичность.

Ключевые слова: проза Эффенди Капиева, эпитеты-прилагательные, метафорический эпитет, семантические группы эпитетов, эпитеты-колоративы, художественные образы.

Важной специфической чертой художественного стиля является образность речи. Образные средства языка помогают автору выразить свое мировоззрение. По словам Ш.А. Мазанаева, занимающегося проблемой двуязычия в художественном творчестве, «для создания истинно талантливого произведения... нужно овладеть целым арсеналом изобразительно-выразительных средств, нужно преподнести мудрую мысль в совершенной форме» [6, с. 121]. Таким арсеналом выразительных средств в совершенстве владел известный дагестанский писатель-билингв Эффенди Капиев. Язык его произведений - это язык профессионального мастера, владеющего тончайшими оттенками образной речи $[6$, с. $120 ; 12$, с. $62 ; 3]$. Литературоведы и лингвисты отмечают специфичность, экспрессивность и колоритность языка и стиля художника слова $[1 ; 7 ; 11 ; 14]$. Тем не менее проблема языковых средств автора, благодаря которым достигается высокий уровень художественного изображения, остается неразработанной [1]. Этим и объясняется выбор объекта нашего исследования: функционально-семантическая характеристика эпитетов-прилагательных 
Гасанова Г.А. Эпитеты как одно из основных средств создания художественных образов в произведениях Э. Капиева

прозаических произведениях Э. Капиева.

Материалом для исследования послужил сборник произведений Э. Капиева «Избранное» [5].

Одним из основных средств создания художественных образов в произведениях Эффенди Капиева являются эпитеты - яркие, образные определения [4, с. 4]. Эпитеты тесно взаимодействуют с гиперболами, метонимией, метафорами и другими изобразительными средствами. Они усиливают полисемичность высказывания и зачастую оригинальны, т. к. являются выражением идиостиля писателя. В.А. Маслова отмечает их связь с культурой народа, особенностями его мировосприятия, менталитета. В этом смысле прилагательные-эпитеты являются микрофрагментами языковой картины мира [8].

Эпитеты чаще всего выражаются прилагательными, хотя в произведениях художественной литературы встречаются эпитеты-существительные, эпитеты-наречия, эпитеты-глаголы.

Выделяют эпитеты с прямым значением и метафорические эпитеты, употребляемые в переносном значении, в которых выражается авторская оценка изображаемого предмета, явления, лица. Метафорический эпитет основан на сравнении, сопоставлении.

Прилагательные-эпитеты помогают полнее раскрыть тот или иной образ, детально подчеркнуть отличительные свойства предметов, придать описанию образность, яркость, передать настроение писателя.

В прямых и переносных значениях в произведениях Э. Капиева употребляются как качественные, так и относительные прилагательные.

Широко представлены эnитеты-колоративы, что свидетельствует об особенном изобразительном языке автора. Ср.:

Белье, шагающие на глазах, как пена, округлые облака стоят над горами $[5$, c. 69].

Над кораблём нависли мощные тяжёлье черные тучи, готовые вот-вот рухнуть в море [5, с. 339].

Он сидит, прикрыв глаза, точно слушая биение своего сердия... По щзеке его ползёт светлая слеза [5, с. 83].

Тогда шофёр, голубоглазый, с чернылм лицом юнома, оглядывается на Сулеймана и, видя, что по лииу поэта текут слёзы, и не зная, как быть, резко тормозит машину [5, c. 62].

Рукава его [Сулеймана] нового бешмета просторны, и при этом смуглая рука его обнажается до локтя [5, с. 60].

Среди цветовых эпитетов-прилагательных чаще всего встречаются эпитеты желтый, красньий, синий.

Он поднимает плеть на коня, не дожидаясь удара, прыгает вперёд. Сулейман рассекает жёлтую метель падающих листьев [5, с. 52].

Дорога кочковата и усеяна упавшими с возов жёлтылми колосьями [5, с. 57].

Временами над передним краем взлетает немецкая ракета, и всё вокруг

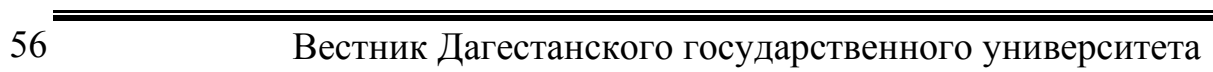

Серия 2. Гуманитарные науки. 2019. Том 34. Вып. 3 
Гасанова Г.А. Эпитеты как одно из основных средств создания художественных образов в произведениях Э. Капиева

освещается пустым и безжизненным, как во сне, жёлтым иветом [5, с. 86]. В данном примере дана необычная характеристика жёлтого извета (пустой и безжизненный), основанная на сугубо личных ассоциациях писателя.

Они (цыллята) катятся, как жёлтые шарики [5, с. 40].

Автор даёт очень трогательное сравнение маленьких существ с жёлтыми круглыми комочками.

Жёлтая пыль и солома летят навстречу машине [5, с. 64].

Капиев очень точно подбирает цветовые эпитеты при описании объектов, окружающих героев. Без них, конечно, образы были бы тусклыми и невыразительными. Сравним два предложения с эпитетом и без для подтверждения сказанного:

1) Сулейман рассекает жёлтую метель падающих листьев [5, с. 58]. - Сулейман рассекает метель падающих листьев.

2) Они (цыплята) катятся, как жёлтыле шарики [5, с. 40]. - Они (цыплята) катятся, как шарики.

Наличие эпитетов обеспечивает зрительное восприятие того, что описывает художник слова. Делает описание выразительным, ярким и запоминающимся: жёлтый песок, жёлтая солома, жёлтые шарики (иыплята), жёлтый свет. Однако восприятие одного и того же цвета самим автором может быть разным. С одной стороны, это цвет солнца, цвет осенних листьев, цвет сена, соломы, цыплят, вызывающие в нас положительные эмоции, так как всё это связано с мирной жизнью. И другое, прямо противоположное восприятие жёлтого цвета, характеризующего цвет немецкой ракеты, при взлёте которой «всё вокруг освещчается пустым и безжизненным, как во сне, жёлтымм иветом».

Для создания зрительных образов используется вся палитра оттенков красного цвета:

А на западе, далеко-далеко заходит солнце... Красный дым стелется по земле... [5, c. 250].

Каждой весной, когда розовый яблоневый цвет ложился на подоконники и карнизы сакли, подобно холодной заре... [5, с. 80].

Сулейман жил в багровой полутьме [5, с. 86].

Багровый - «красный цвет густо-тёмного оттенка» [10, с. 33].

...обнажает тёмно-красную, сочную, как гранат, сердиевину [5, с. 380].

Уходящее солнще висит над садами в розовой мгле [5, с. 98].

Оно (облако) тёмно-вишнёвого ивета, и от него ложатся на придорожные травы лёгкие тени [5, с. 42].

Тёмно-вишнёвыц - «тёмно-красный с лиловатым оттенком; цвета зрелой вишни» $[10$, c. 85$]$.

Чтобы обозначить оттенки цветов, Э. Капиев, помимо простых цветообозначений, употребляет и сложные: тёмно-вишнёвый, тёмно-красный, густо-синий, тёмно-синий и др.

И небо густо-синее, как море на детских рисунках, лежит вдали [5, с. 82].

Над горами расстилаются дымчато-голубые облака [5, с. 53].

Оригинальные цветовые образы созданы в следующих контекстах: 
Гасанова Г.А. Эпитеты как одно из основных средств создания художественных образов в произведениях Э. Капиева

Облака на закате извета персикового сока, медные, затем лиловые [5, с. 289].

Глухая даль, высокие горы ивета луженой меди, однообразный рёв реки внизу таков Акцегер, новоявленный дикий курорт на Кавказе [5, с. 47].

Возникает ассоциация, основанная на сходстве цвета гор с цветом луженой меди «светло-серый оттенок с ярким металлическим блеском».

Имеет место и переносное употребление эпитетов-колоративов.

«Cпасите!» - кричу я тогда, обезумев. Мною овладевает чёрный страх... [5, c. 206].

Цветовое прилагательное «черный» употреблено в переносном метафорическом значении «мрачный, тяжёлый». Данный эпитет характеризует эмоциональное состояние человека.

«Ах, вот оно что! - кивнул Сулейман, глаза его стали тускльми. - Вон оно что! Тут, оказывается, не шуточное дело...» [5, с. 94].

Потускневшие глаза свидетельствуют о разочаровании героя.

Встречаются и производные от имён существительных относительные прилагательные в метафорических значениях, актуализирующие значение цвета. В подобных случаях происходит их окачествление, то есть переход в разряд качественных. Ср.: Здравствуйте, золотые жужжашие пчель моей страны [5, с. 65].

Данное метафорическое значение основано на сходстве цвета пчел с цветом золота, которое в контексте получает символический смысл.

Золотое сияние цуарит в комнате [5, с. 34].

Метафора основана на признаках цвета и блеска золота. Золотое сияние в комнате, видимо, от яркого солнечного света. Возникает ассоциативная связь с солнцем, жёлтым, как золото.

Над горами облака парчовые: сине-розовые с жёлтым [5, с. 72].

Метафорический образ соотносится с вещным кодом культуры, а именно с тканью. Парча - это дорогая ткань, являющаяся для горских женщин символом богатства. Из парчи в прежние времена шили платье для невесты, в котором она присутствовала в главный день свадьбы на площади в центре села.

Автор удивительно точно передаёт цветовую гамму данной ткани, хотя, на первый взгляд, очень трудно определить её цвет, так как в нём сочетаются несколько оттенков, как в радуге.

В ходе анализа материала выявилось немало эпитетов, характеризуюших внешность героев, в частности глаза, лицо, губы, волосы и т. д. Ср.: Этот добродушный толстяк с изрытым оспой красным лицом и узкими глазами [5, с. 92].

Юноши по одному начинают выводить коней ближе к шоссе, где, сдерживая белого жеребия в поводу, стоит горбоносый тёмный знаменщик [5, с. 130].

Тогда шофёр, голубоглазый, с чёрным личом юноша, оглядывается на Сулеймана и, видя, что по лииу поэта текут слёзы и, не зная, как быть, резко тормозит машину [5, с. 61].

Круглое с красныли щеками, тёмное личо её выражает волнение. Большие чёрные глаза дерзко прищурены [5, с. 67]. 
Гасанова Г.А. Эпитеты как одно из основных средств создания художественных образов в произведениях Э. Капиева

Встретилось немало примеров, где описываются борода и усы горцев.

Чернобородый тучный мужчина, к которому обращён этот вопрос, хмурит брови [5, с. 145].

Со стороны мостика, направляясь к нему, идет напрямик через заросли лопуха низенький старик с длинной белой бородой [5, с. 151].

Впереди, выпрямясь, на горячем скакуне сидит сумрачный капитан с длинными седьми усами [5, с. 251].

Стройный барабанщик и седой, с гигантскими усами зурнач вешают поводья на луки своих седел [5, с. 54].

Борода особо почитается у горцев, являясь символом зрелости мужчины, его жизненного опыта. Они могли брить налысо голову, но бороду - никогда. Самая серьезная клятва мусульман: клянусь бородой Пророка! [8, с. 135].

Таким образом, с помощью эпитетов, характеризующих внешний облик героев, вырисовывается обобщённый образ горца, в котором отражаются характерные внешние черты: нос с горбинкой, тёмные глаза, усы и длинная борода, смуглое загорелое под горячим южным солнцем тело.

Одежда горцев тоже отличается своим колоритом. Ср.:

Одетый в ветхую шинель, в огромной папахе и домотканых пыльных обмотках ... [5, c. 93].

Сулейман сидит у ворот, накинув на плечи свой старый бешмет и надев на босые ноги галоши [5, с. 37].

Колоритность облика Сулеймана Стальского, приехавшего в Москву, подчёркивает и сам автор в следующем контексте:

Экзотическая фигура Сулеймана, в шубе и в лохматой горской папахе, привлекает всеобщее внимание [5, с. 222].

Для произведений Э. Капиева, как видно из примеров, характерны подробные, детальные описания героев, в которых даётся внешняя и внутренняя характеристика человека. По словам Н.С. Тихонова, «в центре внимания в произведениях Э. Капиева... описание аульской жизни и общества, характера горского народа» [13, с. 5].

В стороне, в каменной нише ворот, сидит в шубе высокий костлявый старик, греясь на солнце. Он почти сливается с камняли: и белая борода, и округлые складки шубы, и неподвижное серое лицо $[5$, с. 128].

Лицо его мгновенно приобретает землистый оттенок. Оно серьёзно и замкнуто [5, с. 127].

Бледный цвет лица передаётся метафорическим эпитетом землистый, внутреннее состояние - эпитетами в краткой форме.

Старик смотрит вверх на Сулеймана. Одеревенелое лицо его неподвижно. Пухлье, пепельного ивета глаза его еле теплятся мыслью [5, с. 99].

В данном контексте автор использует метафорический эпитет одеревенелое в значении «безжизненное, неподвижное», второе значение в тексте эксплицируется; пепельного ияета в значении «серый». Теплятся - это эпитет-глагол в значении «в скрытом виде, незаметно». 
Гасанова Г.А. Эпитеты как одно из основных средств создания художественных образов в произведениях Э. Капиева

Многочисленны эпитеты, дающие психологическую $u$ эмоцииональную характеристику: (Сулейман) тих и уравновешен; мрачное безразличие; сияющий и гордый, бледный и взволнованный и др.

Примеры контекстов с данными эпитетами:

В этот день Сулейман, против моего ожидания, необычайно тих и уравновешен [5, c. 209].

- Что, - спросил он с мрачным безразличием. - Трава, что ли, ядовитая выросла в этом году? Отчего гибнет скот? [5, с. 93].

Сулейман, сияющий и гордый, вышел провожать юношу за порог [5, с. 102].

И, постучав трубкой о пепельнииу, чтобы стряхнуть пепел, он на мгновение становится величаво-строгим, неприступным [5, с. 180].

По русскому обычаю умерших чтут, снявши папахи, и музыка должна бы играть в это время скорбный мотив [5, с. 140].

Пример интересен тем, что вместо ожидаемого слова шапка употреблена лексема nanaxa. Очевидно, здесь имеет место влияние дагестанских реалий и исторических традиций носить папахи (гендерный символ).

Они (друзья) рассказали мне печальную весть [5, с. 25].

Покачиваются в поле печальные чветы [5, с. 365].

Часто такие эпитеты-прилагательные сочетаются с существительными глаза, взгляд, лищо.

Глаза, лицо также могут выражать внутренние черты характера человека, его эмоциональное состояние: величаво-спокойное лицо; добродушно-приветливое лицо; печальные глаза.

Она (старуха) что-то хочет возразить, но, глянув на замкнутое величавоспокойное личо Сулеймана, уходит в саклю, забыв на ступеньках иветы [5, с. 162].

Сулейман замечает старика, и личо его сразу становится не то ироническим, не то добродушно-приветливым [5, с. 126].

- Отчего у вас такие печальные глаза? [5, с. 366].

Материал показывает, что эпитеты, дающие психологическую и эмоциональную характеристику, могут быть простыми: скорбная птища; недовольный, скорбный мотив; печальная весть; мрачное безразличие; дерзкая мысль; хмурые думы; суровое лицо, и сложными: величаво-строгий; добродушно-приветливое лицо; внушительно-серьёзное выражение.

Используются прилагательные-эпитеты в полной и краткой формах: бледный, злой, гордый, мрачный, печальный, весёльй, озорной; суровы и тверды [лица], тих и уравновешен [Сулейман].

В зависимости от того или иного значения эпитеты могут выражать как положительную, так и отрицательную оценку различных явлений природы, поведения человека, образа жизни. Это так называемые оценочные эпитеты: изящный чемоданчик; замечательный момент (в жизни героя); радостный день; достойные люди; чудесное утро; крепкая сакля; бессовестный человек, недобрая весть и др. Ср. примеры фразового употребления эпитетов:

60 
Гасанова Г.А. Эпитеты как одно из основных средств создания художественных образов в произведениях Э. Капиева

На земле редки достойные люди, как и серебро [5, с. 203].

После болезни так непередаваемо сладок и свеж этот мир, чудесное утро! $[5$, c. 56].

- Ну, что ж, - заключает Сулейман, вдруг оживляясь радостно, - работайте! Крепкая сакля! [5, с. 158].

Чёрт бы побрал этого бессовестного парикмахера, из-за него сегодняшний день пропал [5, с. 88].

Холодным январским днём в аул прискакал гонеи. То был гонеи с недоброй вестью [5, c. 61].

Ряд эпитетов-прилагательных характеризуется наличием в их семантике интенсифицирующей семы. Гиперболический эпитет такого типа намеренно преувеличивает какой-либо признак предмета с максимализацией обозначаемой реалии, которая вызывает особую эмоциональную реакцию автора:

Вдали на камнях в великом безмолвии сидят старики, одетые в иубы или закутанные в изветные одеяла [5, с. 86].

И велики и торжественны судьбы моего поколения [5, с. 426].

Ручей был мал. Он нёс в себе крохотное одинокое счастье из глубин прошлого и впадал в широкое великое море сегоднямнего дня [5, с.137].

Я думаю о Москве. Нет, не о древности и не о сказочных красотах этого города, но о том, как далеко видна эта столица на земле [5, с. 166].

Просторное небо космической чистоты [5, с. 237].

Громовой хохот сотрясает гору, как взрыв. Хохот, приумноженный эхом скал и ущелий, звучит далеко в окрестностях, и кажется, что смеётся весь мир [5, с. 177].

Автор использует эпитеты и для описания тех или иных объектов: яркие крылатые одежды - изящный чунгур; стальной гребень; призрачные (стены города); пестрый узелок; старомодная трубка; ветхий бешмет и др.

Девушки, уже успевшие было отойти на порядочное расстояние, вдруг, остановившись, оглядываются назад. Яркие крылатые одежды их треплет ветер [5, c. 130].

На столбе висят папаха, кнут, мужская одежда и изящный, разукрашенный перламутром чунгур [музыкальныий щипковый инструмент] [5, с. 130].

Старуха, не отвечая, продолжает расчёсывать шерсть на зажатом между колен стальном гребне [5, с. 59].

Он стоит, отвернувшись, возле старика, который в эту минуту, сосредоточенно посапывая, развязывает пёстрый узелок у себя на поясе [5, с. 64].

Через правое плечо его были перекинуты пёстрые хурджсины [распространенная в быту гориев сумка, состоямая из двух мешков] [5, с. 93].

Медленно поднимается в гору арба. Скрипят, переваливая через кочки, огромные деревянные колёса $[5$, с. 43].

Приведенные примеры интересны тем, что здесь описываются реалии горского быта.

Национально-культурная лексика помогает автору передать особенности местного 
Гасанова Г.А. Эпитеты как одно из основных средств создания художественных образов в произведениях Э. Капиева

колорита, придать произведениям реалистичность.

Особо следует выделить группу эпитетов, характеризующих окружающую героев обстановку и природные явления.

С их помощью Э. Капиев рисует удивительные картины родной природы, родного края. Ср.: тихий и весельй ручеек, буйные сады; сонныле улицы аула; стремительные ливни; каменистые обрывы; величественные горы; черные непроницаемые тучи; прозрачные клубы дыма; каменистые дороги; безлюдные ущелья; раннее влажное утро; неторопливая мятная прохлада.

Ручеёк, по-прежнему тихий и весёльй, течёт по камням [5, с. 71].

Деревья стоят вокруг поэта в покорной величавости... [5, с. 151].

И небо такое чёрное, но сад зелёный и светльй весь [5, с. 207].

Стремительный ливень обрушивается на садын... [5, с. 112]

Безлюдное ущелье, ясное небо, тишина [5, с. 61].

Вокруг него стоят погружённые в дрему, величественные горы [5, с. 41].

Разрастается иельй щебечущий, буйный сад [5, с. 366].

Чёрные, непроницаемые тучи подступают к горам, и гор уже не видно [5, с. 77].

В камыших мериает сонная вода [5, с. 272].

Раннее влажное утро. Свежая улича пуста [5, с. 319].

Меня ведёт к себе старик, председатель колхоза, с фонарём в руке. Тихие, сонные улииь аула [5, с. 367].

Из примеров видно, что эпитеты здесь носят преимущественно метафорический и индивидуально-авторский характер. Использование таких эпитетов способствует персонификации объектов окружающего мира.

Проведенное исследование свидетельствует о том, что эпитеты в произведениях Э. Капиева выполняют различные функции: образно характеризуют и индивидуализируют явления, предметы и лица; дают представление о характерах и особенных чертах персонажей; помогают понять их душевный мир. Капиевские эпитеты, преимущественно индивидуально-авторские, создают яркие, национальноспецифичные, неповторимые художественные образы. Несомненна и их лингвокультурологическая значимость.

\section{Литература}

1. Гаджиева A.A. Проблемы семантико-полевого и структурного анализа глагольной лексики (на материале прозы Эффенди Капиева): автореф. дис. ... канд. филол. наук. - Махачкала, 2005. - 21 с.

2. Гасанова Г.А. Образ красивого человека в русской языковой картине мира (на материале фразеологических и паремиологических единиц) // Мир науки, культуры, образования. - 2017. - № 6 (67). - С. 482-484.

3. Гасанова Г.А., Омарова С.О. Образные языковые средства в книге Э. Капиева «Поэт» // Мир науки, культуры, образования. - 2019. - № 3 (76). - С. 540-542.

4. Горбачевич К.С., Хабло Е.П. Словарь эпитетов русского литературного языка. Л.: Наука, 1979. - 567 с. 
Гасанова Г.А. Эпитеты как одно из основных средств создания художественных образов в произведениях Э. Капиева

5. Капиев Э. Избранное. - М.: Художественная литература, 1959. - 664 с.

6. Мазанаев Ш.А. Двуязычное художественное творчество в системе национальных литератур. - Махачкала: Юпитер, 1997. - 264 с.

7. Мамедова Л.В. Проблемы поэтики Э. Капиева (Книга новелл «Поэт»): автореф. дис. ... канд. филол. наук. - Махачкала, 1998. - 23 с.

8. Маслова В.А. Лингвокультурология. - М., 2004. - 208 с.

9. Москвин В.П. Эпитет как предмет теоретического осмысления // Электронный научно-образовательный журнал ВГПУ «Грани познания». - 2011. - № 4 (14). - С. 1-5. http://grani.vspu.ru/files/publics/1325227875.pdf

10. Ожегов С.И., Шведова Н.Ю. Толковый словарь русского языка. - М., 2005. $944 \mathrm{c}$.

11. Сантуева Э.3. Особенности функционирования русского языка в художественной литературе лакских писателей: автореф. дис. ... канд. филол. наук. - Махачкала, 1999. - 18 с.

12. Тамадаева Х.Б. Эфенди Капиев. Жизнь и творчество. - Махачкала, 1962. $144 \mathrm{c}$.

13. Тихонов Н.С. Слово об Э. Капиеве // Э. Капиев. Избранное. - М., 1959.

14. Халилов Х.М. Фольклор в художественной системе Эффенди Капиева // Э. Капиев и его роль в развитии дагестанской советской литературы. - Махачкала, 1981.

\section{Referens}

1. Gadzhiev A.A. Problems of semantic and structural analysis of verbal vocabulary: On the material of Effendi Kapiev's prose: Abstract. dis. ... cand. filol. sciences. - Makhachkala, 2005. $-21 \mathrm{p}$.

2. Hasanova G.A. The image of a beautiful person in the Russian language picture of the world (based on phraseological and paremiological units) // World of Science, Culture, Education. - 2017. - № 6 (67). - P. 482-484.

3. Hasanova G.A., Omarova S.O. Figurative language means in the book by E. Kapiev "Poet" // World of science, culture, education. - 2019. - № 3 (76). - P. 540-542.

4. Gorbachevich K.S, Khablo E.P Dictionary of epithets of the Russian literary language. - L.: Nauka, 1979. - 567 p.

5. Kapiev E. Selected works. - M.: Fiction. 1959. - 664 p.

6. Mazanaev Sh.A. Bilingual art in the system of national literatures. - Makhachkala: Jupiter, 1997. - $264 \mathrm{p}$.

7. Mamedova L.V. Problems of poetry by E. Kapiev. (The book of short stories "Poet"). Abstract. dis. ... cand. filol. sciences. - Makhachkala, 1998. -23 p.

8. Maslova V.A. Linguoculturology. - M., 2004. - 208 p.

9. Moskvin V.P. Epithet as a subject of theoretical understanding // Electronic scientific and educational journal of VSPU "The verge of knowledge". - 2011. - № 4 (14). - P. 15 http://grani.vspu.ru/files/publics/1325227875.pdf

10. Ozhegov S.I., Shvedova N.Yu. Explanatory dictionary of the Russian language. - M., 2005. -944 p. 
Гасанова Г.А. Эпитеты как одно из основных средств создания художественных образов в произведениях Э. Капиева

11. Santueva E.Z. Features of the functioning of the Russian language in the literature of Lak writers: Abstract. dis. ... cand. filol. sciences. - Makhachkala, 1999. - 18 p.

12. Tamadaeva H.B. Effendi Kapiev. Life and creation. - Makhachkala, 1962. - 144 p.

13. Tikhonov N.S. On E. Kapievs works // E. Kapiev. Favorites. - M., 1959.

14. Khalilov H.M. Folklore in the artistic system of Effendi Kapiev // E. Kapiev and his role in the development of Dagestan Soviet literature. - Makhachkala: B.I., 1981.

Поступила в редакичю 19 июля 2019 г.

UDC 894.612.6.Kapiev.06

DOI: $10.21779 / 2542-0313-2019-34-3-55-64$

\title{
Epithets as the means of creating artistic images in the works by E. Kapiev
}

\begin{abstract}
G.A. Gasanova
Dagestan State University; Russia, 367000, Makhachkala, M. Gadzhiev st., 43a; gulistan160459@mail.ru

The article discusses epithets-adjectives based on the material of prose works by Effendi Kapiev, the famous Dagestan bilingual writer. Kapiev's various epithets-adjectives are different in their semantics and structure and contribute to the expressive and emotional portrayal of the characters as well as their surrounding nature. In the writer's works epithets-coloratories are widely represented which testify the special exspressive language of the author. Attention is drawn to individual author's metaphorical epithets with the help of which the author creates original, vivid, nationally specific artistic images. The national cultural specificity of Kapiev epithets is noted. The epithets describing the realities of mountain life and the nature of the native land are particularly highlighted, testifying his great love for the motherland. In his works, the author also uses national and cultural vocabulary, which helps the author convey the peculiarities of local color giving the works realism.
\end{abstract}

Keywords: Effendi Kapiev's prose, epithets-adjectives, metaphorical epithet, semantic groups of epithets, color epithets, artistic images.

Received 19 July, 2019 